\title{
Avaliação da taxa de incidência anual de dengue no município de Salvador-BA entre anos de 2007 a 2019 e delineamento do perfil epidemiológico nos anos de 2011 e 2013
}

\author{
Evaluation of the annual incidence rate of dengue in the city of Salvador-BA between \\ years 2007 to 2019 and delineation of the epidemiological profile in the years 2011 \\ and 2013
}

Caroline Stephanie Neves Vera ${ }^{1 *}$, Ivy de Figueiredo Espinheira Almeida ${ }^{1}$, Rafael Oliveira Santana ${ }^{2}$, Samilly Silva Miranda ${ }^{3}$

\begin{abstract}
${ }^{1}$ Acadêmica do Curso de Nutrição da Universidade Federal da Bahia (UFBA); ${ }^{2}$ Acadêmico do Bacharelado Interdisciplinar de Humanidades da UFBA; ${ }^{3}$ Mestre e Doutora pela Universidade Estadual de Feira de Santana (UEFS) e Professora Adjunta de Saúde Coletiva da UFBA
\end{abstract}

\begin{abstract}
Resumo
Objetivo: avaliar a taxa de incidência anual da dengue no município de Salvador-BA entre os anos de 2007 a 2019, de modo a descrever o perfil sociodemográfico da população acometida e traçar o perfil epidemiológico nos anos de 2011 e 2013 que correspondem, respectivamente, ao ano de maior e menor taxa de incidência da doença. Metodologia: trata-se de um estudo epidemiológico cujos dados foram obtidos de fontes secundárias, através do Tabnet Salvador. Foram incluídas variáveis sociodemográficas, clínicas e distribuição sazonal dos casos de dengue. Resultados: foram notificados 76.227 casos de dengue na região estudada durante o período de 2007 a 2019, cujos anos de 2011 e 2013 observou-se a predominância do nível de escolaridade fundamental/médio incompleto. Conclusão: o retrato geográfico da dengue deve servir de alerta sobre o comportamento da enfermidade, a fim de evidenciar a necessidade de medidas mais efetivas relativas às ações de controle, vigilância e tratamento da doença, sendo de fundamental importância o desenvolvimento de estratégias com enfoque na atenção primária à saúde objetivando a conscientização da população através de ações educativas e abordagens midiáticas, e fazendo-se necessário a compreensão do papel de fatores socioeconômicos e ambientais e suas importantes implicações para a implementação de medidas efetivas de prevenção e combate ao mosquito vetor. Palavras-chaves: Dengue. Epidemiologia Descritiva. Arboviroses.
\end{abstract}

\begin{abstract}
Objective: to evaluate the annual incidence rate of dengue in the city of Salvador-BA between the years 2007 to 2019, in order to describe the sociodemographic profile of the affected population and to trace the epidemiological profile in the years 2011 and 2013 that correspond, respectively, the year with the highest and lowest incidence rate of the disease. Methodology: this is an epidemiological study whose data were obtained from secondary sources, such as Tabnet Salvador and includes sociodemographic, clinical variables and seasonal distribution of dengue cases. Results: 76.227 cases of dengue were reported in the studied region during the period from 2007 to 2019, whose years from 2011 to 2013 the predominance of the level of incomplete primary/secondary education was observed. Conclusion: the geographic portrait of dengue should serve as a warning about the behavior of the disease, in order to highlight the need for more effective measures related to the control, surveillance and treatment of the disease, with the development of strategies focusing on primary care being of fundamental importance. to health aiming at population awareness through educational actions and media approaches and making it necessary to understand the role of socioeconomic and environmental factors and their important implications for the implementation of effective measures to prevent and combat the vector mosquito. Keywords: Dengue. Descriptive Epidemiology. Arbovirus Infections.
\end{abstract}

\section{INTRODUÇĀO}

A Dengue é uma doença febril aguda, de etiologia viral que é transmitida pelo Aedes aegypti, principal mosquito vetor. A existência de quatro sorotipos é conhecida (DENV-1, DENV-2, DENV-3 e DENV-4), sendo que a doença pode apresentar desde uma evolução benigna na forma clássica, até uma evolução grave quando se apresenta na forma hemorrágica ou com complicações ${ }^{1}$.

Correspondente/Corresponding: ${ }^{*}$ Caroline Stephanie Neves Vera ${ }^{1}-$ End: Rua Eulálio de Oliveira, número 31, apartamento 202, Salvador -BA -Tel: (71) 99133-4846-E-mail: carol_stephanienv@hotmail.com
Atualmente, trata-se de uma das arboviroses (doença viral transmitida por vetores artrópodes) mais importantes no Brasil e no mundo devido a sua alta incidência, uma vez que, estima-se que mais da metade da população mundial vive em países endêmicos de dengue e, verifica-se, sobretudo nos países tropicais, cujas condições do meio favorecem a proliferação do mosquito. Fatores biológicos e ambientais, bem como aqueles relacionados à dinâmica social e à pressão seletiva sobre vetores e vírus, têm contribuído para o aumento da incidência em áreas endêmicas, para 
a ocorrência de surtos e de epidemias, assim como para a introdução do patógeno em novas regiões ${ }^{2}$.

A Organização Mundial da Saúde estima que ocorrem cerca de 50 a 100 milhões de casos de dengue em todo o mundo anualmente e que, aproximadamente, 2,5 bilhões de pessoas vivem em países endêmicos ${ }^{3}$. No Brasil, até a Semana Epidemiológica (SE) 12 (30/12/2018 a $23 / 03 / 2019)$, a região Sudeste apresentou o maior número de casos prováveis de dengue (179.714 casos; $65,7 \%)$ em relação ao total do país, tendo a região Nordeste se destacado em terceiro lugar com 20.543 casos que compuseram $7,5 \%$ do total de notificações ${ }^{4}$.

Como doença endêmica reemergente, a dengue afeta principalmente países de regiões tropicais e subtropicais do planeta que são mais suscetíveis devido a alguns fatores condicionantes como alterações climáticas, variabilidade do clima, armazenamento de água e irrigação, além do crescimento da população e urbanização ${ }^{5}$.

Tanto o crescimento dos aglomerados urbanos com condições precárias de habitação e abastecimento de água, quanto as condições climáticas intensificadas pelo aquecimento global são considerados fatores importantes no que se diz respeito ao aumento da transmissão da doença pelo mosquito vetor ${ }^{6}$.

Em decorrência da inviabilidade da erradicaçāo completa do Aedes aegypti, o Ministério da Saúde ressalva o quão imprescindível é o seu controle para redução da densidade viral. Assim, o estudo da dengue e sua caracterização comparando-se os anos de maior e menor incidência fornece informações bases para a descrição epidemiológica da doença, o que é essencial para o planejamento de ações que visam minimizar a ocorrência de novos casos e favorecer a busca pela erradicação do vetor?

Na Bahia, entre 1994 e 2000, houve notificações em todas as mesorregiões do estado. Os municípios que apresentaram maiores números de notificações e as maiores taxas de incidência da doença foram aqueles situados próximos ao litoral, os mais urbanizados (como Salvador), aqueles situados próximos da BR-101, com elevadas taxas de densidade populacional e outros ${ }^{7}$.

Nessa perspectiva, esta pesquisa tem por objetivo avaliar a taxa de incidência anual de dengue no município de Salvador, no estado da Bahia, entre os anos de 2007 a 2019, fornecendo maior destaque para os anos de 2011 e 2013 de modo a exibir o comportamento da doença no que diz respeito, respectivamente, ao ano de maior e menor taxa de incidência da arbovirose em questão, bem como descrever o perfil sociodemográfico da população acometida.

\section{METODOLOGIA}

O presente artigo traz um estudo epidemiológico de abordagem descritiva, com natureza quantitativa de séries temporais da ocorrência dos casos de dengue na cidade de Salvador, no estado da Bahia, entre os anos 2007 a 2019. 0 estado da Bahia possui 15.126.371 habitantes distribuídos em 417 municípios com características sociais, econômi- cas, demográficas, culturais e epidemiológicas distintas. Pelo último senso realizado em 2018, a populaçāo do município de Salvador encontra-se estimada em 2.857.329 habitantes, sendo sua área equivalente à $692,818 \mathrm{~km}^{2} \mathrm{e}$ cuja densidade demográfica é de $4.124,21 \mathrm{hab} . / \mathrm{km}^{2} \mathrm{com}$ um clima característico do tipo tropical atlântico ${ }^{8}$.

Os dados foram obtidos de fontes secundárias, a partir do Sistema de Informação de Salvador (Tabnet Salvador), que trata-se de uma plataforma de domínio público desenvolvido pelo DATASUS (departamento de informática do Sistema Único de Saúde do Brasil) para gerar informações das bases de dados do Sistema Único de Saúde. Os dados acerca da dengue disponibilizados neste sistema de informação são oriundos das fichas de notificação compulsória, desenvolvidas para alimentar o Sistema de Informação de Agravos de Notificação (SINAN) no período que corresponde a doze anos (2007-2019). Foi utilizada ainda a base de dados do Instituto Brasileiro de Geografia e Estatística (IBGE), local este onde foram coletadas as informações referentes ao contingente populacional.

A princípio, o número de casos por ano nesse intervalo de tempo foi coletado a fim de se calcular as taxas anuais de incidência no município, sendo traçado o perfil epidemiológico da dengue no ano de maior e menor taxa de incidência. Portanto, a partir dos valores encontrados, tais anos, especificamente, foram selecionados para melhor análise e descrição, a fim de mostrar o comportamento da doença e a caracterização da população. As informações de investigação do Sistema incluem dados sociodemográficos, bem como classificação final e evolução da doença. Os dados foram coletados até o mês de maio de 2019 , pois no período da coleta de dados o referido ano ainda apresentava dados inconclusos.

As variáveis sociodemográficas incluídas foram: sexo, faixa etária, raça, zona de residência, nível de escolaridade; As epidemiológicas consistiram em: mês de notificação (janeiro a dezembro), classificação da doença (clássica, dengue com complicação, febre hemorrágica), casos autóctones, forma grave e óbitos, bem como classificação final e evolução da doença.

Os dados foram exportados para o Excel, onde foram calculadas a taxa de incidência anual da dengue referente a cada período informado. Os resultados referentes à análise estatística foram apresentados em formatos de gráficos e tabelas. Como refere-se a um estudo com dados secundários agregados e públicos, não houve necessidade de envio ao Comitê de Ética em Pesquisa.

\section{RESULTADOS}

No período de 2007 a 2019, foram 83.294 casos de dengue na região estudada, onde, de acordo com a figura 1 , se observou uma maior ocorrência da doença entre os anos de 2011 e 2012, os quais apontaram uma taxa média de incidência equivalente a 34 casos por 10.000 habitantes em ambos os anos, compondo assim, $28,4 \%$ do total de registros. Já no ano de 2013, observou-se uma redução 
drástica na incidência da doença na cidade de Salvador com uma média de 10 casos por 10.000 habitantes, sendo que, nesse período, o número de casos compôs uma parcela de $1,4 \%$ do número total de registros.

Figura 1 - Taxa de incidência de Dengue por 10.000 habitantes, no período de 2007-2019, Salvador, Bahia, Brasil

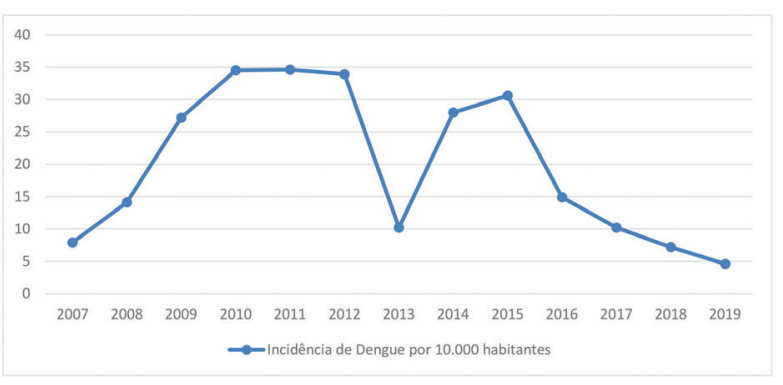

Fonte: Secretaria Municipal de Saúde/Tabnet Salvador.

O perfil sociodemográfico dos casos de dengue nessa populaçāo no ano de 2011 se caracterizou por um predomínio de $4.748(51,3 \%)$ casos do sexo feminino, 2.868 e 3.176 nas faixas etárias, respectivamente, de 15 a 29 (representando $31 \%$ dos casos) e de 30 a 59 anos (representando $34,3 \%$ dos casos), 3.756 ( $40,5 \%)$ da raça parda/ negra e $1.034(11,2 \%)$ com nível de escolaridade ensino fundamental/médio incompleto. No ano de 2013, o perfil dos casos caracterizou-se por predominarem 1.502 (51\%) casos do sexo masculino, $1.072(36,4 \%)$ na faixa etária de 15 a 29 anos, 789 (26,8\%) da raça parda/negra e 172 $(5,8 \%)$ com nível de escolaridade fundamental/médio incompleto (Tabela 1).

Tabela 1 - Distribuição de casos de dengue notificados segundo variáveis sóciodemográficas nos anos de 2011 e 2013, Salvador, Bahia, Brasil

\begin{tabular}{lrrrr}
\hline \multicolumn{1}{c}{ Variáveis } & \multicolumn{2}{c}{$\mathbf{2 0 1 1}$} & $\mathbf{2 0 1 3}$ \\
& $\mathbf{N}$ & \% & N & \% \\
\hline Sexo & & & & \\
Feminino & 4.748 & 51,3 & 1.430 & 49,0 \\
Masculino & 4.50 & 48,7 & 1.502 & 48,6 \\
Vazio/Ignorado & 5 & 0,0 & 12 & 0,4 \\
Faixa Etária & & & & \\
Menor de 1 ano & 202 & 2,2 & 77 & 2,6 \\
1 a 14 anos & 2.745 & 29,7 & 620 & 21,1 \\
15 a 29 anos & 2.868 & 31,0 & 1.072 & 36,4 \\
30 a 59 anos & 3.176 & 34,3 & 1.063 & 36,1 \\
Acima de 60 anos & 271 & 2,8 & 112 & 3,8 \\
Raça & & & & \\
Amarela & 27 & 0,3 & 10 & 0,3 \\
Branca & 422 & 4,5 & 126 & 4,3 \\
Indígena & 16 & 0,2 & 2 & 0,1 \\
Parda/Negra & 3.756 & 40,5 & 789 & 26,8 \\
Vazio/Ignorado & 5.041 & 54,5 & 2.017 & 68,5 \\
Nível de Escolaridade & & & &
\end{tabular}

\begin{tabular}{lrrrr} 
Fundamental/Médio incompleto & 1.034 & 11,2 & 172 & 5,8 \\
Fundamental Completo & 211 & 2,3 & 42 & 1,4 \\
E. Médio Completo & 599 & 6,5 & 128 & 4,3 \\
E. Superior & 170 & 1,8 & 67 & 2,3 \\
Analfabetos & 10 & 0,1 & 3 & 0,1 \\
Vazio/Ignorado & 7.238 & 78,1 & 2.532 & 86,1 \\
\hline
\end{tabular}

Fonte: Secretaria Municipal de Saúde/Tabnet Salvador.

Segundo as variáveis epidemiológicas, os meses de maior notificação no ano de 2011 foram maio com 1.719 $(18,5 \%)$ casos, junho com $1.599(17,3 \%)$ casos e julho com $1.123(12,1 \%)$ casos. Já no ano de 2013, os meses de maior notificação foram abril com $397(13,5 \%)$ casos, maio com $304(10,3 \%)$ casos e junho com $282(9,6 \%)$ casos conforme observado na figura 2 .

Figura 2 - Distribuição Sazonal da Dengue, nos anos de 2011 e 2013, Salvador, Bahia, Brasil

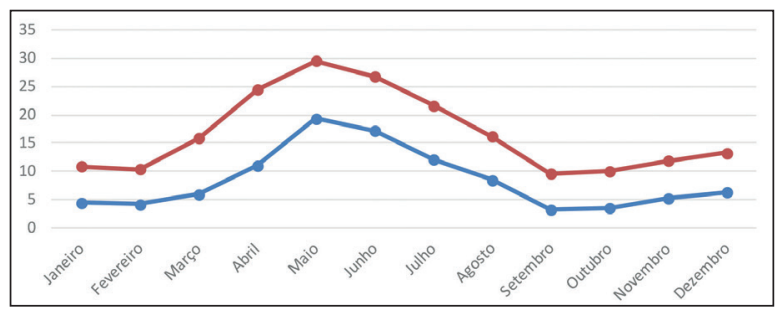

Fonte: Secretaria Municipal de Saúde/Tabnet Salvador.

Quanto à classificação da dengue, tanto no ano de 2011 quanto no ano de 2013, prevaleceram os casos de dengue clássica com 3675 (39,9\%) e $810(27,5 \%)$ casos, respectivamente. Em 2011, foram notificados 110 (1,2\%) casos na forma da dengue com complicações, 5 (0,1\%) óbitos e 1.977 (21,3\%) casos autóctones, enquanto que em 2013, os valores encontrados foram de $14(0,5 \%)$ notificações na forma de dengue com complicações, 2 $(0,1 \%)$ óbitos e $418(14,2 \%)$ casos autócnes de acordo com o exposto na tabela 2.

Tabela 2 - Distribuição de casos de dengue notificados segundo variáveis clínicas nos anos de 2011 e 2013. Salvador, Bahia, Brasil

\begin{tabular}{lrrrr}
\hline \multicolumn{1}{c}{ Variáveis } & \multicolumn{2}{c}{2011} & \multicolumn{2}{c}{2013} \\
& N & \% & N & \% \\
\hline Classificação Final & & & & \\
Dengue Clássica & 3675 & 39,7 & 810 & 27,5 \\
Dengue com Complicações & 110 & 1,2 & 14 & 0,5 \\
Febre Hemorrágica /Síndrome do & 69 & 0,7 & 11 & 0,4 \\
Choque do Dengue & & & & \\
Descartado/Inconclusivo & 5208 & 56,3 & 2097 & 71,2 \\
Vazio/Ignorado & 200 & 2,1 & 12 & 0,4 \\
Casos autócnes & 1977 & 21,3 & 418 & 14,2 \\
Óbito & 5 & 0,1 & 2 & 0,1 \\
\hline
\end{tabular}

Fonte: Secretaria Municipal de Saúde/Tabnet Salvador. 


\section{DISCUSSĀO}

O presente estudo apresenta uma caracterização geral dos casos de dengue na cidade de Salvador no período de 2007 a 2019. Conforme os dados observados, o número de notificações no ano de 2007 mostrava-se relativamente baixo em relação à população total nesse período. Com o passar dos anos houve um aumento, inicialmente gradativo e, posteriormente, mais significativo no número de casos que atingiu seu ápice no ano de 2011, quando o número de notificações teve um aumento relativamente alto em relação ao ano inicial. No ano de 2012 esse valor elevado se manteve, sofrendo apenas uma reduçāo mínima, sendo que, apenas no ano de 2013 que realmente se verificou uma redução significativa de $68 \%$ no número de casos em relaçāo ao ano anterior. A redução pode ter sido em decorrência da ampliação das campanhas de conscientização populacional, da implantação da Estratégia Global para Prevenção e do Controle da Dengue pela $\mathrm{OMS}^{9}$.

No final do ano de 2013 para início do ano de 2014 notou-se um aumento no investimento em campanhas audiovisuais de prevenção e controle do Aedes aegypti além da intensificação de medidas para identificação de casos. Nas regiões com registro da febre da dengue, foram constituídas equipes, composta por técnicos das secretarias locais, para orientar a busca ativa de casos suspeitos e emitir alerta às unidades de saúde e às comunidades. Para controle dos mosquitos transmissores da doença, foram realizadas ações de bloqueio de casos suspeitos e eliminação de criadouros ${ }^{10}$. No entanto, não foi somente no Brasil que a implementação de tais medida trouxeram resultados satisfatórios. Neste mesmo ano observou-se uma redução dos casos de dengue em países como a Índia, por exemplo, devido a execução de programas de irradicação e melhorias nas condições de água encanada e saneamento básico ${ }^{11}$.

Apesar dos avanços no controle da doença no Brasil, nos anos de 2014 para 2015 houve um aumento significativo na incidência da doença, devido a uma diminuição na verba que era destinada às prefeituras para ações de combate ao mosquito Aedes aegypti. Estima-se que houve uma redução de cerca de $20 \%$ no recurso. No ano de 2016, no entanto, esses índices voltaram a melhorar, registrando uma redução de cerca de $50 \%$ no número de casos notificados que se mantiveram em queda até o ano de $2019^{12}$.

Os resultados obtidos da análise temporal da incidência da doença no período indicado (2007-2019) apontaram então o ano de 2011 como o de maior número de notificações contrastando com o ano de 2013 em que houve o menor número de registros de ocorrência da doença com 6.318 casos a menos.

O perfil sociodemográfico das notificações de dengue na cidade de Salvador no ano de 2011 caracterizou-se por predominarem casos do sexo feminino, enquanto que em 2013 predominaram-se casos do sexo masculino. A faixa etária adulta prevaleceu em ambos os anos variando de 15 a 59 anos em 2011 e 15 a 29 anos em 2013. O predomínio da alta taxa da doença entre as mulheres pode estar diretamente relacionado com a maior permanência destas no domicílio, local de preferência do mosquito Aedes aegypti por sua característica urbana ${ }^{13}$.

Resultados semelhantes foram encontrados na cidade de Cuiabá-MT entre os anos de 2007 e 2011 com maior notificação de casos do sexo feminino (53,0\%), embora a faixa etária predominante nesse estudo tenha sido entre 5 e 14 anos $(25,1 \%)^{14}$. Contudo, é importante destacar que esta doença não está relacionada ao sexo e, por isso, resultados divergentes são encontrados, como pode ser observado nos índices apresentados no boletim epidemiológico da Bahia referente ao ano de 2015 que apresentaram frequência de $59 \%$ nos casos do sexo masculino ${ }^{15}$.

A raça parda/negra também prevaleceu para os dois períodos e podemos conceder como possível justificativa para essa questão a vulnerabilidade social, atribuindo um maior risco para as pessoas pretas e pardas quando comparadas às pessoas brancas, por exemplo ${ }^{16}$. Vale mencionar o número de subnotificações por não preenchimento/fator ignorado desta variável que mostrou-se bastante elevado equivalendo a $54,5 \%$ do total de registros em 2011 e 68,5\% do total de registros em 2013 e o não preenchimento adequado também pode ter vindo a interferir no número total de notificações.

Quanto à variável escolaridade, em ambos os anos de 2011 e 2013, assim como observado em relação à raça, a maioria das notificações também não foram preenchida. Essa subnotificação do nível de escolaridade, é umas das questões que devem ser discutidas por profissionais e gestores em saúde, considerando a importância do conhecimento desta variável no desenvolvimento de medidas de intervenção e controle da dengue ${ }^{17}$.

Na dengue, assim como em outras diversas doenças, a educação é um pilar fundamental para o controle, prevenção e promoção integrados. Esse determinante deve ser considerado no desenvolvimento de políticas públicas que possam reduzir constantemente a doença e seu impacto nas regiões endêmicas. Um estudo realizado na região caribenha da Colômbia mostrou uma associação entre o nível de educação, conhecimento, atitudes e práticas em relação à dengue. Os resultados desse estudo apresentaram que os egressos do ensino médio apresentaram maior frequência de respostas corretas em relação ao conhecimento sobre sintomas e transmissão da dengue. E quanto aos graduados, os mesmos apresentaram maior probabilidade de práticas e atitudes que favorecem 0 controle da dengue, incluindo o não armazenamento de água em contêineres ${ }^{18}$.

Portanto, podemos dizer que o nível educacional pode ser um determinante essencial do conhecimento da doença e sua transmissão, bem como atitudes e práticas, especialmente aquelas que envolvem a integração da comunidade e esforços para o controle da dengue. Esse estudo realizado na Colômbia sugeriu ainda que popu- 
lações com baixo nível educacional são especialmente vulneráveis e sua integração em programas de controle pode ser particularmente difícil. Portanto, a priorização dessas populações em programas voltados ao controle da dengue e de outros arbovírus seria justificada ${ }^{19}$.

Os meses de maior notificação em 2011 e 2013 foram abril, maio, junho e julho, início do inverno, sendo este considerado um período de grande variabilidade climática na cidade de Salvador, cujo clima é marcado pela oscilação entre dias quentes e chuvosos. ${ }^{19}$ Assim, possivelmente, os níveis de infestação de vetores, bem como a maior incidência da doença coincidiram com este intervalo.

A identificação precoce dos casos de dengue é de importância crucial para o controle de epidemias. O vírus da dengue causa um espectro variado de doenças que inclui desde formas inaparentes ou subclínicas, até quadros de hemorragia que podem levar ao choque e ao óbito ${ }^{20}$. Por tal motivo, é de extrema importância ressaltar que houve uma distribuição acerca da apresentação clínica da dengue, onde foi apresentado os casos diagnosticados de dengue clássica e com complicações, demonstrando assim, a gravidade das ocorrências, além de apresentar os casos notificados de óbito por dengue e transmissão autócne (ocorrida dentro do território nacional).

Em estudo que analisou os casos de dengue na Bahia, no período de 1994 a $2000^{21}$, os municípios com maiores taxas de detecção de casos foram aqueles mais urbanizados e com maior densidade populacional, entre eles, Salvador, Lauro de Freitas e Madre de Deus. O estudo reforça ainda que nas cidades com menores índices populacionais, provavelmente, as condições de proliferação não sejam tão favoráveis para o Aedes aegypti, sendo assim menor o potencial de transmissão do vírus da dengue ${ }^{22 .}$

Entender essa concentração é fundamental a fim de explicar o número crescente de casos em determinadas épocas, associando a condições precárias de saneamento, educação e outros fatores culturais, para assim determinar locais de ações de combate ao vetor Aedes aegypti. Seus criadouros preferenciais são recipientes artificiais, tanto aqueles abandonados a céu aberto, que servem como reservatório de água de chuva, como os utilizados para armazenar água para uso doméstico. A presença dos criadouros em ambiente de convívio com o homem favorece a rápida proliferação da espécie, por dois aspectos: condições ideais para reprodução e fontes de alimentação ${ }^{22}$.

Uma revisão de Racloz et al. ${ }^{23}$ destacaram os benefícios da combinação de fatores climáticos, ambientais, epidemiológicos e socioeconômicos para prever surtos e, assim, fornecer tempo para atividades de prevenção e controle ${ }^{23}$ No entanto, Bowman, Runge-Ranzinger e Mccall ${ }^{24}$ encontraram poucas evidências de uma associação quantificável entre os índices de populações de mosquitos e a transmissão da dengue que poderia ser usada com segurança para prever surtos ${ }^{24}$. Isso reflete uma falta histórica de associação entre parâmetros entomológicos e epidemiológicos da dengue e desafia a utilidade ope- racional de modelos preditivos em muitos contextos ${ }^{25}$.

O combate a este vetor envolve ações continuadas de inspeções domiciliares, eliminação e tratamento de criadouros, associadas a atividades de educação em saúde e mobilização social ${ }^{26}$. A finalidade das ações de rotina é manter a infestação do vetor em níveis incompatíveis com a transmissão da doença. Em situações de epidemias, deve ocorrer a intensificação das ações de controle, prioritariamente a eliminação de criadouros e o tratamento focal. Além disso, deve ser utilizada a aplicação espacial de inseticida a ultrabaixo volume (UBV), ao mesmo tempo em que as ações de rotina são conduzidas de forma aprimoradas. Em função da complexidade que envolve a prevenção e o controle da Dengue, o Programa Nacional de Controle da Dengue estabeleceu dez componentes de ação: vigilância epidemiológica; combate ao vetor; assistência aos pacientes; integração com a atenção básica; ações de saneamento ambiental; ações integradas de educação em saúde, comunicação e mobilização; capacitação de recursos humanos; legislação de apoio ao Programa; acompanhamento e avaliação. Esses componentes de ação, se convenientemente implementados, contribuirão para a estruturação de programas permanentes, integrados e intersetoriais, características essenciais para o enfrentamento deste importante problema de saúde pública ${ }^{22}$.

A limitação deste estudo consiste na possibilidade de subregistro dos dados, o que dificulta a reprodução da realidade. É imprescindível que todos os campos existentes nas fichas de notificação sejam adequadamente preenchidos ${ }^{27}$ a fim de evitar informações contraditórias. É possível que tenha ocorrido ainda subnotificação no que tange aos sinais e sintomas mais leves. Muitos indivíduos acometidos pela doença tendem a tratá-la em sua própria casa, e, portanto, não existem notificações pelos serviços de saúde para estes casos.

Ademais, a relação entre níveis socioeconômicos e transmissão de dengue precisa ser melhor investigada e, talvez, ela dependa da realidade de cada município/ bairro. Apesar destas questões não estarem diretamente vinculados à transmissão do vetor, fatores como a educação podem influenciar a maior predominância de casos, uma vez que, a mesma funciona como prática prioritária de prevenção no combate da dengue. Os dados revelaram uma considerável discrepância no que tange à escolaridade. A maioria dos indivíduos apresentava escolaridade incompleta e isso reforça a influência da educação no controle do número de casos. Embora a ciência tenha evoluído nos estudos sobre a doença, é perceptível que a maior eficiência no combate da dengue é a prevenção, e nesse quesito, a educação é a ponte entre a população e os meios de prevenir a proliferação dos $\operatorname{casos}^{21}$. Para isso, a campanha de combate a dengue promovida pelo Ministério da Saúde demonstrou significativa eficiência na redução do número de casos de 2011 para 2013, e assim, o fortalecimento dessas campanhas mostra-se essencial para o combate ainda mais efetivo da doença, promovendo um foco maior nas 
regiões de maior número de casos e populações com menores níveis de escolaridade ${ }^{22}$.

\section{CONCLUSÃO}

Os achados desse trabalho contribuem para a compreensão do comportamento da dengue na cidade de Salvador-BA no intervalo de anos de 2007 a 2019, com descrição do perfil sociodemográfico da população acometida e delineamento do perfil epidemiológico da arbovirose na região estudada nos anos de 2011 e 2013 como sendo os anos, respectivamente, de maior e menor incidência da doença e com o objetivo de alertar a população, os pesquisadores e serviços de saúde acerca da dinâmica da enfermidade.

Apesar dos constantes investimentos das instituições de saúde no combate ao vetor e da identificação de uma gradativa redução na incidência a partir do ano de 2016, o número de casos registrados ainda mostra-se elevado e a dengue continua como importante agravo com constantes períodos epidêmicos na capital baiana. Nesse sentido, fica evidente a necessidade de medidas mais efetivas no que diz respeito às ações de controle, vigilância e tratamento da doença, sendo de fundamental importância, nesse âmbito, o desenvolvimento de estratégias com enfoque na atenção primária à saúde objetivando a conscientização populacional através de ações educativas nas escolas e abordagens midiáticas.

Além disso, destaca-se a importância da capacitação das equipes de saúde para melhor notificação e diagnóstico da doença, assim como um aperfeiçoamento da investigação epidemiológica a fim de evitar a subnotificaçāo de casos que interfere diretamente nos resultados quanto a real situação atual da dengue.

Especificamente, os resultados deste estudo sugerem que as campanhas educacionais se concentrem principalmente nas pessoas com baixa escolaridade, levando em consideração as distintas faixas etárias e populações vulneráveis que se localizam em áreas de maior risco e que são afetadas consistentemente a cada ano. Portanto, faz-se necessário à compreensão do papel de fatores socioeconômicos e ambientais e o impacto destes na ocorrência da dengue. Intervenções direcionadas podem ser mais eficientes e ter maior impacto nas atitudes e práticas preventivas.

\section{AGRADECIMENTOS}

A nossa orientadora Samilly Silva Miranda, pelo empenho dedicado à elaboração deste trabalho. Obrigada pelas suas correções e incentivos, por nos manter motivados durante todo o processo e pelo suporte no pouco tempo que the coube.

\section{REFERÊNCIAS}

1. ORGANIZAÇÃO PAN-AMERICANA DE SAÚDE. Dengue. Organização Mundial da Saúde. Brasil. Disponível em: https://www.paho.org/bra/ index.php?option=com_content $\&$ view=article $\&$ id $=416$ :dengue $\&$ Item id=463. Acesso em: 15 maio 2019.

2. SECRETARIA DO ESTADO DE SAÚDE DE SÃO PAULO. Diretrizes para a prevenção e controle das arboviroses urbanas no estado de São Paulo. Disponível em: http://portal.saude.sp.gov.br/resources/cve-centro-de-vigilancia-epidemiologica/areas-de-vigilancia/doencas-de-transmissao-por-vetores-e-zoonoses/dengue.htm. Acesso em: 15 maio 2019.

3. WORLD HEALTH ORGANIZATION. Dengue: guidelines for diagnosis, treatment, prevention and control. Who Library and Digital Information Networks. New Edition, 2009. p. 1-160. Disponível em: https://apps. who.int/iris/bitstream/handle/10665/44188/9789241547871_eng. pdf?sequence=1\&isAllowed=y. Acesso em: 15 maio 2019.

4. BRASIL. Ministério da Saúde. Secretaria de Vigilância em Saúde. Monitoramento dos casos de arboviroses urbanas transmitidas pelo Aedes (dengue, chikungunya e Zika) até a Semana Epidemiológica e Levantamento Rápido de Índices para Aedes aegypti (LIRAa). Bol. Epidemiol., Rio de Jnaeiro, v. 50, n. 13, p. 1-18, Abr. 2019. Disponível em: http:// portalarquivos2.saude.gov.br/images/pdf/2019/abril/30/2019-013-Monitoramento-dos-casos-de-arboviroses-urbanas-transmitidas-pelo-Aedes-publicacao.pdf. Acesso em: 15 maio 2019.

5. SUTHERST, R. Global change and human vulnerability to vector-borne diseases. Clin Microbiol. Rev., Estados Unidos, v. 17, n.1, p. 136-173, Jan. 2004. Disponível em: https://www.ncbi.nlm.nih.gov/pmc/ articles/PMC321469/. Acesso em: 15 maio 2019.

6. MINISTÉRIO DA SAÚDE. Secretaria de Vigilância em Saúde. Departamento de Vigilância Epidemiológica. Biblioteca Virtual em Saúde. Diretrizes nacionais para prevenção e controle de epidemias de dengue. Brasília, p. 1-160. 2009. (Série A. Normais e Manuais Técnicos, n. 1) Disponível em: http://bvsms.saude.gov.br/bvs/publicacoes/diretrizes_ nacionais_prevencao_controle_dengue.pdf. Acesso em: 15 maio 2019.

7. MELO, M. et al. Progressão da circulação do vírus do dengue no Estado da Bahia, 1994-2000. Rev. Soc. Bras. Med. Trop., Brasília, v. 43, n. 2, p. 139-144, Mar-Abr. 2010. Disponível em: https://repositorio.ufba. br/ri/bitstream/ri/2457/1/repos2010.36.pdf. Acesso em: 15 maio 2019.

8. INSTITUTO BRASILEIRO DE GEOGRAFIA E ESTATÍSTICA. Panorama. Disponível em: https://cidades.ibge.gov.br/brasil/ba/salvador/panorama. Acesso em: 28 maio 2019.

9. MINISTÉRIO DA SAÚDE. Casos de dengue caem $59 \%$ e óbitos 40\% em 2014. Disponível em: https://www.saude.gov.br/noticias/ svs/16192-casos-de-dengue-caem-59-e-obitos-40-em-2014. Acesso em 19 maio 2019.

10. CORREIA, T. et al. Prevalência de dengue clássica e dengue hemorrágica no Brasil, entre 2011 e 2015. Rev Elet Acervo Saúde/EJCH., Montes Claros-MG, v. 22, n. 753, p. 1-8. Nov. 2018. Disponível em: https://acervomais.com.br/index.php/saude/article/view/753/372. Acesso em 18 jun 2020.

11. MUTHENENI, S. et al. Spatial distribution and cluster analysis of dengue using self organizing maps in Andhra Pradesh, India, 2011-2013. Paras. Epidemiol. and Control., Índia, v. 3, n. 1, p. 52-61. Fev. 2018. Disponível em: https://www.sciencedirect.com/science/article/pii/ S2405673116300228. Acesso em 18 jun 2020.

12. BACELAR, C. Verba para combate à dengue caiu $\mathbf{2 0 \%}$ de $\mathbf{2 0 1 4}$ para 2015. Disponível em: https://oglobo.globo.com/rio/verba-para-combate-dengue-caiu-20-de-2014-para-2015-19243518. Acesso em 18 jun. 2020.

13. GIBSON, G. et. al. From primary care to hospitalization: clinical warning signs of severe dengue fever in children and adolescents during an outbreak in Rio de Janeiro, Brazil. Cadernos de Saúde Pública, Rio de Janeiro, v. 29, n. 1, p. 82-90. 2013. Disponível em: https://www.arca. fiocruz.br/handle/icict/10528. Acesso em 30 maio 2019. 
14. GUOLLO, D. et. al. Aspectos epidemiológicos da dengue em Cuiabá-MT entre 2007 e 2011. Estudos, Goiânia, v. 42, n. 4, p. 503-516. 2015. Disponível em: http://seer.pucgoias.edu.br/index.php/estudos/article/ viewFile/4368/2503. Acesso em 30 maio 2019.

15. DA SILVA, A.; DE OLIVEIRA, G. The registry of diseases of compulsory notification: the participation of health professionals and the community. Rev. Epidemiol. Control. Infect., Rio Grande do Sul, v. 4, n. 3, p. 215220. 2014. Disponível em: http://dx.doi.org/10.17058/reci.v4i3.4578. Acesso em 30 maio 2019.

16. MINISTÉRIO DA SAÚDE. Secretaria de Vigilância em Saúde. Bol. Epidemiol., Rio de Janeiro, v. 46, n. 10, p. 1-35. 2015. Disponível em: http://www.saude.gov.br/images/pdf/2015/abril/22/Boletim-raca-cor-09-04-15-v2.pdf. Acesso em 18 jun 2020.

17. SECRETARIA DE SAÚDE DO ESTADO DA BAHIA. Situação Epidemiológica da dengue, chikungunya e dei/zika, 2015. Disponível em: http://www.saude.ba.gov.br/wp-content/uploads/2017/11/Boletim-epidemiol\%C3\%B3gico-n\%C2\%BA-03-dengue_chikungunya_zika-2.pdf. Acesso em 31 maio 2019.

18. DIAZ-QUIJANO, F. et al. Association between the level of education and knowledge, attitudes and practices regarding dengue in the Caribbean region of Colombia. BMC Public Health. Colômbia, v. 18, n. 143, p. 1-10. 2018. Disponível em: https://www.ncbi.nlm.nih.gov/ pmc/articles/PMC5771071/pdf/12889_2018_Article_5055.pdf. Acesso em: 19 jun.2020.

19. VARELLA, D. Dengue clássica, dengue hemorrágica e dengue com complicações. Disponível em: https://drauziovarella.uol.com.br/ drauzio/artigos/dengue-classica-dengue-hemorragica-e-dengue-com-complicacoes-artigo/. Acesso em: 31 maio 2019.

20. MARENGO, J. et al. Variabilidade e mudanças climáticas no semiárido brasileiro. Recursos Hídricos e Regiões Áridas e Semiáridas. Instituto Nacional do Semiárido, Campina Grande, v. 1, n. 1, p. 383-416. 2011. Disponível em: http://plutao.sid.inpe.br/col/ dpi.inpe.br/plutao/2011/06.11.02.16/doc/Marengo_Variabilidade. pdf?languagebutton=en. Acesso em: 4 jun. 2019.
21. VASCONCELOS, P. et. al. Epidemia de dengue em Ipupiara e Prado, Bahia. Inquérito soro-epidemiológico. Rev. Soc. Bras. Med. Trop., Brasília, v. 33, n. 11, p. 61-67, Jan-Fev. 2000. Disponível em: http://www. scielo.br/pdf/rsbmt/v33n1/v33n1a09.pdf. Acesso em: 7 jun. 2019.

22. BRASIL. Ministério da Saúde. Secretaria de Vigilância em Saúde. Departamento de Vigilância Epidemiológica Biblioteca virtual em saúde. Doenças infecciosas e parasitárias: guia de bolso. Brasília, 2010. P. 1-444. (Série B. Textos Básicos de Saúde, n. 8). Disponível em: http:// bvsms.saude.gov.br/bvs/publicacoes/doencas_infecciosas_parasitaria_guia_bolso.pdf. Acesso em: 8 jun. 2019.

23. RACLOZ, V. et al. Surveillance of dengue fever virus: areview of epidemiological models and early warning systems. PLoS Negl. Trop.Dis., Estados Unidos, v. 6, n. 5, p. 1-9, Maio 2012. Disponível em: https:// www.ncbi.nlm.nih.gov/pmc/articles/PMC3358322/pdf/pntd.0001648. pdf. Acesso em: 19 jun.2020.

24. BOWMAN, L.; RUNGE-RANZINGER, S.; MCCALL, P. Assessing the relationshipbetween vector indices and dengue transmission: a systematic review of theevidence. PLoS Negl. Trop. Dis., Estados Unidos, v. 8, n. 5, p. 1-11, Mai. 2014. Disponível em: https://www.ncbi.nlm.nih.gov/pmc/ articles/PMC4014441/pdf/pntd.0002848.pdf. Acesso em: 19 jun. 2020.

25. EBI, K.; NEALON, J. Dengue in a changing climate. J. Environ. Res., Washington, v. 1, n. 151, p.115-123, July 2016. Disponível em: https://www.sciencedirect.com/science/article/pii/ S0013935116303127. Acesso em: 20 jun. 2020.

26. LI, Q. et. al. Spatiotemporal responses of dengue fever transmission to the road network in an urban area. J. Acta Trop., China, v. 1, n. 183, p. 8-13, Mar. 2018. Disponível em: https://www.sciencedirect.com/ science/article/abs/pii/S0001706X17311294. Acesso em: 20 jun. 2020.

27. MINISTÉRIO DA SAÚDE. Sistema de Informação de Agravos de Notificação (SINAN). Ficha de Investigação - Dengue e Febre de Chikungunya. 2016. Disponível em: http://portalsinan.saude.gov.br/ images/documentos/Agravos/Dengue/Ficha_DENGCHIK_FINAL.pdf. Acesso em: 21 jun. 2020.

Submetido em: 06/12/2019

Aceito em: 10/09/2020 